\title{
Value of Pulse oximetry screening for early detection of critical congenital heart diseases in sohag University hospital
}

Authors:Dr. SafaaHusein Ali; Assistant Professor of pediatrics,Faculty of Medicine, Sohag University.

Dr. Mohammad Ahmad Hassan; Lecturer of Pediatrics, Faculty of Medicine, Sohag University

\section{Corresponding authors:AmrAtef Mohammad;}

\begin{abstract}
:
Background: Cardiovascular malformations are the commonest form of congenital defects and could result in significant morbidity. Antenatal and early postnatal detection is still unreliable, especially in developing countries and low-income communities. Pulse oximetry (PO) could have an important value in the detection of cardiac lesions among asymptomatic newborns.

Patients and methods: This was prospective observational study conducted at nursery units at Sohag university hospital and Sohag general hospital. Over a period of one year, the period from October 2016 through October 2017. Oxygen saturation was measured by pulse oxymetery. Echocardiography was done for babies with positive screening within $24 \mathrm{~h}$ of screening

Results: The study included 830 apparently-well babies, there were 25 babies (3\%) show positive screening. Sensitivity of POS for CHD was $88.64 \%$.The specificity was $91.67 \%$. The false-positive rate was $4 \%$, a positive predictive value (PPV) of $92 \%$, a negative predictive value (NPV) of $88 \%$.

Conclusion: Pulse oximetry screening (POS) was found to be safe, simple, noninvasive, reasonably accurate, effective, and has high specificity for early diagnosis of CHD in apparently healthy newborns in our locality.
\end{abstract}

\section{Introduction:}

Congenital heart disease (CHD) is one of the most common birth defects, with an incidence of nine out of every 1,000 live births [1-2]. Although infant mortality has decreased over the past 3 decades for children with all forms of CHD, many children are still diagnosed too late to avoid significant morbidity or death [3-5]. Delayed diagnosis of Critical CHD (CCHD) is unfortunately too common, with up to $25 \%$ of infants with these defects being missed in newborns when identification is based on clinical symptoms or signs of heart disease even in settings with routine prenatal sonograms [6-7]. The screening of CCHD by Pulse oximetry (PO) involves taking advantage of its ability to detect clinical and more importantly subclinical levels of hypoxemia that should raise suspicion for a CCHD. Studies in Europe and the US have suggested that newborn screening with PO testing prior to discharge from the nursery can decrease the number of missed cases by $\sim 30 \%$ [2-9]. In 2011, PO screening for CCHD was added to the Recommended Uniform Screening 
Panel by the Health and Human PO has been the mainstay procedure for indirectly detecting hypoxemia in medically ill patients since the 1980s [13-14].We aimed to study the value of PO screening in detection of critical congenital heart disease in asymptomatic neonates before discharge from the hospital, and to develop suitable protocol for using PO as screening tool for CCHD in our locality.

Patients and method:This was prospective observational study conducted at the nursery units at Sohag university hospital and Sohag general hospital. Over a period of one year; the period from October 2016 through October 2017; the study was approved by the local Ethics Committee. Informed parental written consent was obtained prior to enrollment in the study. There were 4900 newborn babies delivered in Sohag university hospital and Sohag general hospital during the period of study, of which 994 preterm babies, 1216 babies needed NICU admission, 1360 babies refuse screening, 500 missed babies. The sample included 830 apparently-well babies, delivered at (32-40 completed weeks of gestation) irrespective of the mode of delivery. Oxygen saturation $\left(\mathrm{SpO}_{2}\right)$ was measured by pulse oxymetry device (Meditech, China) in both hospitals. Screening was done between 2 hours after delivery till the time of discharge from the hospital. Exclusion criteria included: symptomatic newborns with respiratory distress or cardiovascular instability, dysmorphic feature or any other condition necessitating monitoring or admission to NICU. The measurement was carried out on the right hand and on the right or the left foot, by using portable pulse oximetry which displays fractional oxygen saturation and pulse rate. The
Services Secretary [10-12]. probe was placed for at least $2 \mathrm{~min}$ until a stable recording was obtained. The measurement was carried out by trained medical staff (nurses). Measurements were obtained while the child is calm, warm and not during feeding. We considered the longest, stable reading value of oxygen saturation. The saturation result of $95 \%$ or higher at any measuring point or the difference between the right arm and leg of $5 \%$ or less, was considered as negative screening. Otherwise, the measurement was repeated two more times at intervals of one hour. Persistent saturation below $95 \%$ at any measuring point, or the difference between the measured saturation at two sites is higher than $5 \%$, was considered as positive screening and the child was considered a candidate for a cardiology consultation. Echocardiographic examination was performed by a single operator (Dr. SafaaHusein Ali) using GE Vivid 7 echocardiography machine (GE Medical System, N-3190, Horten, Norway), in standardized views (subcostal, apical, left parasternal and suprasternal), utilizing the two dimensional (2-D), color flow Doppler, continuous wave $(\mathrm{CW})$, pulsed wave (PW) and motion-mode ( $\mathrm{M}$ mode). Cases associated with a significant cardiac lesion were considered as "true-positive", while those associated with insignificant cardiac lesions as patent foramen oval (PFO) or tiny patent ductusarteriosus (PDA) or with normal intracardiac anatomy were considered as "falsepositive".

Data management and statistic analysis: The data of each baby including (name, sex, gestational age, postnatal age, weight, length, type of delivery, heart rate, preductal and postductal oxygen saturation, 
SOHAG MEDICAL JOURNAL

Vol. 22 No. 2 July 2018 echocardiography findings) were collected. Data were collected, coded, revised and entered to the Statistical Package for Social Science (IBM SPSS) version 20. A test of normality was run to all the data to differentiate between data with parametric and nonparametric distribution

Chi-square test was used in the comparison between two groups with qualitative data and Fisher exact test was used instead of the Chi-square test when the expected count in any cell

\section{Results:}

Table 1 shows distribution of demographic data and anthropometric measures of screened babies. The mean age of screening was 58.08 hours $\pm 30.51 \mathrm{~h}$. From screened babies there were $467(56.3 \%)$ male and $363(43.7 \%)$ female. The mean gestational age was 37.5 weaks $(w)$ with Mean $\pm 1.76 \mathrm{w}$, the mean height was $49.12 \pm 2.90 \mathrm{~cm}$ and mean weight was $3.143 .14 \pm 0.73 \mathrm{~kg}$. The range of heart rate was from 111 to 172 beat per minute. The mean oxygen saturation difference between right hand and left foot was $2.68 \%$. From screened babies there were 25 babies (3\%) show positive screening (oxygen saturation pre-ductal and/or post-ductal less than 95\% and/or difference more than 5\%). Echocardiography was done for babies with positive screening within $24 \mathrm{~h}$ of screening. Echocardiography was done for twenty five babies with negative screening and they were considered as control group. The control babies were matched with positive screened group as regard their gestational age \pm one week and for their weight $\pm 500 \mathrm{gm}$. There was no statistically significant difference between both groups as regards demographic data $(\mathrm{P}>0.05)$. Table 2 summarizes echocardiography findings in positive screened group and control group, in positive screened group there were 23 cases with congenital heart disease, two cases (8\%) with isolated ventricular septal defect (VSD), 4 cases (16\%) with isolated patent ductusarteriosus (PDA), 3 cases (12\%) with isolated atrial septal defect (ASD), 4 cases (16\%) with ASD+PDA, 6 cases (24\%) with VSD+PDA, 2 cases (8\%) with VSD+ASD, one case (4\%) with Fallot tetralogy (FT) and one case (4\%) with transposition of great arteries (TGA). In control group there were 2 cases (8\%) with PDA and one case (4\%) with ASD, so there was statistically significant increase in VSD, PDA and ASD in positive screened group in comparison to the control group. Incidence of CHD among screened babies was (3.1\%) from which there were 2 cases with CCHD (.24\%), so there was statistically significant increase in CHD in positive screened group than control group $(\mathrm{P}<0.001)$. Table 3 shows that the true positive cases were 23 , the true negative cases were 22 cases, the false positive cases were two and the false negative cases were 3 , one of them had ASD and two cases had PDA. Sensitivity of POS for CHD was $88.64 \%$ (95\% confidence interval (CI): 76.6 to 92.2). The specificity was $91.67 \%$ (95\% confidence interval (CI): $86.3-100.0)$. The falsepositive (FP) POS was found in two cases (FP rate $=4 \%, 95 \%$ CI: 0.28 to 6.38 ), a positive predictive value (PPV) of $92 \%$ (95\% CI: 81.0 to 99.9 ), a negative predictive value (NPV) of $88 \%$ (95\% CI: $80 \%$ to $99 \%$ ). 
SOHAG MEDICAL JOURNAL

Vol. 22 No. 2 July 2018
Value of Pulse oximetry screening for early detection AmrAtef Mohammad

Table (1):Distribution of demographic data and anthropometric measure in screened cases

\begin{tabular}{|c|c|c|c|}
\hline & & Number & Percentage \% \\
\hline \multirow[t]{2}{*}{ Gender } & Female & 363 & $43.7 \%$ \\
\hline & Male & 467 & $56.3 \%$ \\
\hline \multirow[t]{2}{*}{ MOD } & CS & 690 & $83.1 \%$ \\
\hline & NVD & 140 & $16.9 \%$ \\
\hline \multirow[t]{2}{*}{ Age by hours } & Mean \pm SD & \multicolumn{2}{|c|}{$58.08 \pm 30.51$} \\
\hline & Range & \multicolumn{2}{|c|}{$24-144$} \\
\hline \multirow[t]{2}{*}{ Gestational age } & Mean \pm SD & \multicolumn{2}{|c|}{$37.50 \pm 1.76$} \\
\hline & Range & \multicolumn{2}{|c|}{$34-40$} \\
\hline \multirow[t]{2}{*}{ Height by cm } & Mean \pm SD & \multicolumn{2}{|c|}{$49.12 \pm 2.90$} \\
\hline & Range & \multicolumn{2}{|c|}{$43-59$} \\
\hline \multirow[t]{2}{*}{ Weight by kg } & Mean \pm SD & \multicolumn{2}{|c|}{$3.14 \pm 0.73$} \\
\hline & Range & \multicolumn{2}{|c|}{$2-4$} \\
\hline
\end{tabular}

(MOD, mode of delivery; CS, caesarean section; NVD, normal vaginal delivery; SD, standard deviation)

Table (2):Comparison between studied groups as regards echo finding

\begin{tabular}{|c|c|c|c|c|c|c|}
\hline \multirow[t]{2}{*}{ Echocardiography findings } & \multicolumn{2}{|c|}{$\begin{array}{c}\text { Positive screened group } \\
\text { (No.=25) }\end{array}$} & \multicolumn{2}{|c|}{$\begin{array}{l}\text { Control group } \\
\text { (No.=25) }\end{array}$} & \multicolumn{2}{|c|}{ Chi square test } \\
\hline & No. & $\%$ & No. & $\%$ & $\mathrm{X} 2$ & P-value \\
\hline VSD & 2 & $8 \%$ & $\mathbf{0}$ & $0.0 \%$ & 19.444 & $<0.001$ \\
\hline PDA & 4 & $16 \%$ & 2 & $8 \%$ & 10.702 & 0.005 \\
\hline ASD & 3 & $12 \%$ & 1 & $4 \%$ & 3.947 & 0.047 \\
\hline ASD+PDA & 4 & $16 \%$ & $\mathbf{0}$ & $0.0 \%$ & 1.020 & 0.014 \\
\hline VSD+PDA & 6 & $24 \%$ & o & $0.0 \%$ & 2.040 & 0.013 \\
\hline VSD+ASD & 2 & $8 \%$ & o & $0.0 \%$ & 1.030 & 0.026 \\
\hline TF & 1 & $4.0 \%$ & 0 & $0.0 \%$ & 1.020 & 0.312 \\
\hline TGA & 1 & $4.0 \%$ & o & $0.0 \%$ & 1.020 & 0.312 \\
\hline
\end{tabular}

(VSD, ventricular septal defect; PDA, patent ductusarteriosus; ASD, atrial septal defect; TF, tetralogy of fallot; TGA, transposition of great arteries)

Table (3):Accuracy of POX screening test

\begin{tabular}{|l|c|}
\hline True positive & 23 \\
\hline True negative & 22 \\
\hline False positive & 2 \\
\hline False negative & 3 \\
\hline false positive rate (95\%CI) & $8 \%$ \\
\hline Sensitivity $(95 \% \mathrm{CI})(\%)$ & $91,67(86.3-100.0)$ \\
\hline Specificity $(95 \% \mathrm{CI})(\%)$ & $92(86.3-100.0)$ \\
\hline Positive predictive value $(95 \% \mathrm{CI})(\%)$ & $88(86.3-100.0)$ \\
\hline Negative predictive value $(95 \% \mathrm{CI})(\%)$ & \\
\hline
\end{tabular}




\section{Discussion:}

The study population of the present work was 830 apparently-well babies, delivered at 32-40 completed weeks of gestation, obtained from low socioeconomic community. Typically in this socio-economic community, antenatal follow-up and routine care is not wellapplied, these is also coupled with early postpartum discharge and the absence of proper well-baby routine follow-up. In such setting, a simple, quick, non-costly and readily-available tool for the early detection of possible cardiac defects is of importance. The first hour of life is not suitable for PO testing owing to the large number of false positive findings [15]. Thereafter, infants can be examined at any time, but somewhat more reliably after $2 \mathrm{~h}$ [16]. The protocol applied in our study included POS after 2 hours of life, or as close to discharge as possible to reduce the false positive results that may occur during the first $2 \mathrm{~h}$. The screening was performed by measuring oxygen saturations using pulse oximetry in the right hand (preductal saturation) and one foot (postductal saturation) either concurrently or one immediately after the other. Screening was considered positive or a fail if measurement of oxygen saturation was below $95 \%$ in both extremities, or if there was a difference of more than $5 \%$ in oxygen saturation between preductal and postductal saturations. It is challenging to set the cut off value for a positive test based on several studies [17]. It has been recommended to use a $\mathrm{SpO}_{2}$ value $<95 \%$ in the lower limb (18). $\mathrm{SpO}_{2}$ cut-off of $<95 \%$ is supported by many previous researchers who considered a $\mathrm{SpO}_{2}$ of $<95 \%$, as an appropriate threshold, at repeated measurements to minimize missed cases, as by testing lower cutoffs of $<93 \%$ and $<94 \%$, a considerable number of cases with significant cardiac lesions will be missed [16-18]. Among the screened cases, it was found that $3 \%$ of cases had positive screening results that were referred to the cardiology unit for echocardiography within $24 \mathrm{~h}$ of screening. Most cases had cardiac defects with left to right shunt. One case was diagnosed with Transposition of great arteries (TGA) and one case with Fallot Tetralogy (FT). Our results showed that the true positive cases were 23 cases (92\%), the true negative cases were 22 cases (88\%), the falsepositive (FP) was found in two cases (FP rate $=4 \%, 95 \%$ CI: 0.28 to 6.38 ), and the false negative cases were 3, one of them had ASD and two cases had PDA, the sensitivity of POS for CHD was $88.64 \%$ (95\% confidence interval (CI): 76.6 to 92.2), the specificity was $(95 \%$ confidence interval (CI): 86.3 - 100.0), a positive predictive value (PPV) of $92 \%(95 \%$ CI: 81.0 to 99.9 ), a negative predictive value (NPV) of $88 \%$ (95\% CI: $80 \%$ to $99 \%$ ). Our results were comparable with the results reported in other international studies [19-20-21]. We found that our false-positive result of $4 \%$ was higher than the values reported in the international studies in various countries, including $0.8 \%$ in the UK [19], $0.17 \%$ in Sweden [20], 0.1\% in a large study conducted in Germany [21], 0.026\% in Poland [22] and 0.14\% in Norway [16], the high percentage of false positive in our study may be because of the early screening time 224 hours of age and in some cases before 2 hours of age if the patient was planned for early discharge, Therefor, most publications have recommended that pulse oximetry screening be performed at $\geq 24$ hours 
of age [23-24-25]. However, the falsepositive rate of $(4 \%)$ was lower than that reported by Sattar et al. (55\%) [26] and Schelp et al. (43.8\%) [27]. The high percentage of false positive in their studies may be due to early screening time (within 2 hours of birth) and the non-healthy babies were not excluded. The sensitivity $88.46 \%$ and specificity $91.67 \%$ in our study were close similar to the international studies, $75 \%$ and $99.3 \%$ in a UK [19], $79 \%$ and $99.8 \%$ in Swedish study [20], $77.78 \%$ and $99.9 \%$ in a German study [21], 78.9\% and 99.9\% in Poland [22], and $77.1 \%$ and $99.4 \%$ in Norway [16].

In conclusion:Pulse oximetry can be used as a tool in apparently healthy term newborns for the early detection of cardiac lesions that might necessitate specialized follow-up and care.

\section{References:}

1. Hoffman JI, Kaplan S. The incidence of congenital heart disease. J Am CollCardiol. 2002;39(12):1890-1900.

Mahle WT, Newburger JW, Matherne GP, et al. Committee on Fetus and Newborn Role of pulse oximetry in examining newborns for congenital heart disease. Circulation. 2009;120(5):447-458.

2. Schultz AH, Localio AR, Clark BJ, Ravishankar C, Videon N, Kimmel SE. Epidemiologic features of the presentation of critical congenital heart disease: implications for screening. Pediatrics. 2008;121(4)751 -757 .

3. $\mathrm{Ng} \mathrm{B}$, Hokanson J. Missed congenital heart disease in neonates. Congenit Heart Dis. 2010;5(3):292-296.

5. Riehle-Colarusso T, Strickland MJ, Reller MD, et al. Improving the quality of surveillance data on congenital heart defects in the metropolitan Atlanta congenital defects program. Birth Defects Res
ClinMolTeratol. 2007;79(11):743753.

6. Mahle WT, Martin GR, Beekman RH, 3rd, Morrow WR, Section on Cardiology and Cardiac Surgery Executive Committee Endorsement of Health and Human Services recommendation for pulse oximetry screening for critical congenital heart disease. Pediatrics. 2012;129(1):190192.

7. Wren C, Reinhardt Z, Khawaja K. Twenty-year trends in diagnosis of life-threatening cardiovascular malformations. Arch Dis Child Fetal Neonatal Ed. 2008;93(1):F33-F35.

8. Studer MA, Smith AE, Lustik MB, Carr MR. Newborn pulse oximetry screening to detect critical congenital heart disease. J Pediatr. 2014;164(3):.e1-.e2.

9. De Wahl Granelli A, Mellander M, Sunnegårdh J, Sandberg K, OstmanSmith I. Screening for duct-dependant congenital heart disease with pulse oximetry: a critical evaluation of strategies to maximize sensitivity. ActaPaediatr. 2005;94(11): 1590-1596.

10. Kemper AR, Mahle WT, Martin GR, et al. Strategies for implementing screening for critical congenital heart disease. Pediatrics. 2011;128(5):e1259 -e1267.

11. Garg LF, Van Naarden Braun K, Knapp MM, et al. Results from the New Jersey statewide critical congenital heart defects screening program. Pediatrics. 2013;132(2):e314 -e323.

12. McDermott TL, Vernon MM, Schultz AH. Voluntary implementation of critical congenital heart disease screening in Washington hospitals. HospPediatr. 2015;5(4):193202.

13. Fouzas S, Priftis KN, Anthracopoulos MB. Pulse oximetry in pediatric 
practice. Pediatrics.2011;128(4):740 -752 .

14. Poets CF, Southall DP. Noninvasive monitoring of oxygenation in infants and children: practical considerations and areas of concern. Pediatrics. 1994;93(5):737 -746 .

15. Richmond S, Reay G, Abu-Harb M. Routine pulse oximetry in the asymptomatic newborn.Arch Dis Child Fetal Neonatal Ed 2002; 87: F83-8.

16. Meberg A, Brugmann-Pieper S, Due Jr R, Eskedal L, Fageru I, Farstad T, et al. First day of life pulse oximetry screening to detect congenital heart defects. J Pediatr 2008; 152(6): 5-761.

17. Wren C, Reinhardt Z, Khawaja K. Twenty-year trends in diagnosis of life-threatening neonatal cardiovascular malformations. Arch Dis Child Fetal Neonatal Ed 2008; 93 (1) : F33-5.

18. Ma XJ, Huang GY. Neonatal pulse oximetry screening improves detecting of critical congenital heart disease. Chin Med J 2013; 126 (14): 40-2736.

19. Ewer AK. Review of pulse oximetry screening for critical congenital heart defects in newborn infants. CurrOpinCardiol. 2013;28: 92-96.

20. De-Wahl Granelli A, Wennergren M, Sandberg K, et al. Impact of pulse oximetry screening on the detection of duct dependent congenital heart disease: a Swedish prospective screening study in 39,821 newborns. BMJ. 2009; 338: a3037.

21. Riede FT, Worner C, Dahnert I, Mockel A, Kostelka M, Schneider P. Effectiveness of neonatal pulse oximetry screening for detection of critical congenital heart disease in daily clinical routine-results from a prospective multicenter study. Eur J Pediatr 2010; 169:975-81.

22. Turska-Kmieć A, BorszewskaKornacka MK, Błaż W, Kawalec W, Żuk1 M. Early screening for critical congenital heart defects in asymptomatic newborns in Mazovia

province. KardiologiaPolska. 2012; 70 (4):370-376.

23. ArlettazR, Bauschatz A, Monkhoff M, Essers B, BauersfeldU.The contribution of pulse oximetry to the early detection of congenital heart disease in newborns. Eur $\mathbf{J}$ Pediatr 2006; 165(2):94-8.

24. Thangaratinam S, Brown $K$, Zamora J, Khan KS, Ewer AK. Pulse oximetry screening for critical congenital heart defects in asymptomatic newborn babies: a systematic review and metaanalysis. Lancet. 2012; 379 (9835): 2459-64.

25. Cuzzi S, Bradshaw E. The road to universal pulse-oximetry screening: are we there yet? Pediatrics. 2011;128:e1271e1272.

26. Sattar RA, Salih AF, Hamawandi AM. Role of pulse oximetry screening for detection of life threatening congenital heart defects in newborn. Merit Res $\mathbf{J}$ Med MedSci 2014;2 (2):054-60.

27. Schelp J, Arlettazb R, Hug MI, Balmer C. Neonatal pulse oximetry screening for congenital heart defects in Switzerland: range of pathology in screening-positive individuals. Cardiovasc Med 2012;15 (6):198-201. 